\title{
LIBERALISMO E FINANCIAMENTO DA EDUCAÇÃO EM ADAM SMITH
}

\author{
LIBERALISM AND FINANCING EDUCATION IN ADAM SMITH
}

Paulo Henrique Freitas Maciel ${ }^{1}$
Antonia de Abreu Sousa
Ana Carmita Bezerra de Souza $^{3}$

\section{RESUMO}

Neste artigo evidencia-se as principais ideias que consubstanciam as práticas econômicas liberais, a partir de um autor considerado fundamental para compreensão do liberalismo clássico: Adam Smith. São elas: a concepção natural de sociedade; a origem das desigualdades sociais; as fontes de renda: salários, juros, lucros e renda da terra; o financiamento de atividades pela coletividade, destacando a educação. Propriedade privada e desigualdade social possuem interfaces pouco sutis. A propriedade seria fundamentada no direito dos homens de se apropriar da natureza, através do trabalho. Ou seja, o trabalho é fonte de riqueza e justificativa da propriedade privada. A origem das desigualdades sociais se explica pela laboriosidade de uns enquanto outros preferem o descanso e os prazeres da vida. Considere-se a divisão da sociedade nos segmentos de trabalhadores, proprietários de terra e de capitalista; e também, em alguns casos, um trabalhador pode ser, ao mesmo tempo, patrão e empregado (mesmo que sejam raros, como reconhece Smith), sendo, portanto, proprietário de mais de uma fonte de renda. Smith (1996) defende que o beneficiado com determinada ação a financie. Assim, o Estado pode pagar pela educação na medida em que esta beneficia a todos, pois forma pessoas menos propensas a se rebelar e também porque esses alguns conhecimentos básicos, essenciais para a vida na sociedade comercial, não serão adquiridos pelo próprio trabalhador se o Estado não intervier. O pagamento feito ao professor deve ser incentivado para que seja feito pelo próprio trabalhador, pois do contrário o professor seria negligente com o seu ofício. Tendo uma concepção de sociedade baseada em leis naturais, Smith (1996) concebe o capitalismo e o livre mercado como resultado natural do desenvolvimento humano. Ou seja, a sociedade caminha naturalmente para a formação social baseada no mercado e nas diferenças de classes sociais. A educação e suas implicações se inserem neste contexto.

PALAVRAS-CHAVE: Liberalismo; Financiamento; Políticas Sociais; Educação.

\footnotetext{
ABSTRACT

In this article the main ideas that embody the liberal economic practices are presented, starting

${ }^{1}$ Técnico-administrativo em Educação na Universidade Federal do Cariri; onde exerce a função de economista; especialista em Gestão Pública pela Universidade Estadual do Ceará; mestre e doutorando em Educação Brasileira pela Universidade Federal do Ceará; pesquisador do Laboratório de Estudos sobre Trabalho e Qualificação Profissional - LABOR. E-mail: paulo.freitas@ufca.edu.br

${ }^{2}$ Doutora em Educação Brasileira, pela Universidade Federal do Ceará; pesquisadora do Laboratório de Estudos sobre Trabalho e Qualificação Profissional - LABOR; pesquisadora do Núcleo de Pesquisa em Educação Profissional - NUPEP; professora no Instituto Federal de Educação, Ciência e Tecnologia do Ceará - IFCE. Email: tonia_abreu@hotmail.com

${ }^{3}$ Doutora em Educação Brasileira, pela Universidade Federal do Ceará; pesquisadora Grupo de Pesquisa Interdisciplinar em Ciências da Natureza, Tecnologia e Educação - INCINATE; professora da Universidade Federal do Cariri - UFCA. E-mail: ana-carmita.souza@ufca.edu.br
} 
from an author considered fundamental for understanding classical liberalism: Adam Smith. They are: the natural conception of society; the origin of social inequalities; the sources of income: wages, interest, profits and land rent; the financing of activities by the community, highlighting education. Private property and social inequality have little subtle interfaces. Ownership would be grounded in men's right to appropriate nature through work. That is, work is a source of wealth and justification of private property. The origin of social inequalities is explained by the industriousness of some, while others prefer the rest and pleasures of life. Consider the division of society into the segments of workers, landowners and capitalists; and also, in some cases, a worker may be both employer and employee (even if they are rare, as Smith acknowledges), and is therefore the owner of more than one source of income. Smith (1996) argues that the beneficiary with a certain action to be financed. Thus, the State can pay for education insofar as it benefits all, since it forms persons less likely to rebel and also because those basic knowledge, essential for life in the commercial society, will not be acquired by the worker himself if the State not intervene. The payment made to the teacher should be encouraged to be done by the worker himself, otherwise the teacher would be negligent with his craft. Having a conception of society based on natural laws, Smith (1996) conceives of capitalism and the free market as a natural result of human development. That is, society naturally walks to the social formation based on the market and the differences of social classes. Education and its implications fit into this context.

KEYWORDS: Liberalism. Financing. Social politics. Education.

\section{INTRODUÇÃO}

Uma das principais características do modo de produção capitalista é a mercantilização de quase totalidade das relações sociais. No momento atual deste sistema de produção, no qual predominam as ideias neoliberais, em que a sociabilidade dar-se pelo mercado, mercantilizando-se e privatizando-se bens e serviços que eram antes regulados e providos pelo Estado, faz-se necessária a análise desse fenômeno em suas origens, com o objetivo de compreender as ideias que fundamentam o neoliberalismo. Assim, é que neste artigo discutimos um autor considerado fundamental para compreensão do liberalismo clássico: Adam Smith.

Adam Smith (1723-1790) é um dos representantes, juntamente com David Ricardo, da economia política clássica, escola teórica que se formou a partir da tentativa de compreender a sociedade europeia do século XVIII, na qual estavam vivendo e que passava por profundas transformações nas suas relações de produção. Os clássicos estavam preocupados em analisar como se produz a riqueza social e qual a forma que esta se distribuía entre as classes (proprietários de terra, trabalhadores e capitalistas); como a divisão do trabalho potencializava a produção de mercadorias e como se davam as transações comerciais entre as nações. Também era uma preocupação destes teóricos a forma de organização do Estado e a cobrança de tributos. 
É neste momento de transição da economia feudal para o capitalismo que, de acordo com Manacorda (2010):

Nasce, simultaneamente, a nova ciência da economia política, como análise científica e como "ideologia" destes novos processos: nos seus autores (Smith e Ricardo) são frequentes as considerações sobre os prejuízos que a revolução provoca não somente nos adultos, mas também às crianças, explorando seu trabalho e privando-os de qualquer instrução. $\mathrm{Na}$ análise desses prejuízos estará baseada a "crítica da economia política" promovida pelos socialistas. (MANACORDA, 2010, p. 303).

É nesse contexto de consolidação, em decorrência da Revolução Industrial, da sociedade capitalista na Europa que Adam Smith escreveu, em 1776, sua obra mais importante, A Riqueza das Nações: Investigação sobre sua Natureza e suas Causas. Professor universitário, lecionando lógica e filosofia moral, ele vai escrever uma obra na qual se questiona qual o porquê do enriquecimento nas nações.

Tendo uma concepção de sociedade baseada em leis naturais, Smith (1996) concebe o capitalismo e o livre mercado como resultado natural do desenvolvimento humano. Ou seja, a sociedade caminha naturalmente para a formação social baseada no mercado e nas diferenças de classes sociais. A educação e suas implicações se inserem neste contexto. A partir desta análise, pretende-se evidenciar as principais ideias que consubstanciam as práticas econômicas liberais, baseando na interpretação do autor.

O texto se apresenta em quatro partes. A primeira trata sobre a concepção natural de sociedade, como concebia Smith (1996); na segunda trazemos as explicações dele para a origem das desigualdades sociais; na terceira, explicitamos as fontes de renda: salários, juros, lucros e renda da terra; e na quarta, trataremos sobre o financiamento de atividades pela coletividade, destacando a educação.

\section{CONCEPÇÃO NATURAL DE SOCIEDADE}

O pensamento de Adam Smith e da Economia Política Clássica se distinguem das ideias econômicas anteriores (fisiocracia e mercantilismo) por colocar no trabalho (e na natureza) a origem da riqueza. A fisiocracia tinha a riqueza como sendo originária da natureza (aqui já se vislumbra o trabalho como fonte da essência subjetiva da riqueza) e o mercantilismo, doutrina que os clássicos se colocam contra, tinha no comércio e na acumulação de metais a origem de toda a riqueza.

Locke (2005) vai fundamentar a propriedade privada no trabalho. A partir de uma 
doação original, Deus doou a terra e tudo o que há nela para uso comum e para o sustendo material de todos.

Deus deu-nos de tudo em abundância $(1 \mathrm{Tm} 6,17)$ é a voz da razão confirmada pela revelação. Mas até que ponto ele no-lo deu? Para usufruirmos. Tanto quanto qualquer pessoa possa fazer uso de qualquer vantagem da vida antes que se estrague, disso pode, por seu trabalho, fixar a propriedade. O que quer que esteja além disso excede sua parte e pertence aos outros. Nada foi feito por Deus para que o homem estrague e destrua. (LOCKE, 2005, p. 412).

Nesse sentido, os frutos das árvores, os animais, as águas das fontes são comuns a todos. Assim, Deus deu o direito aos seres humanos de se apropriar, pelo trabalho, de tudo que houvesse na natureza para sua sobrevivência imediata. Não havia a possibilidade de excedente, pois não se poderia colher além daquilo que cada pessoa pudesse consumir sem se deteriorar.

Porém se eles perecessem na posse dele sem serem devidamente usados; se os frutos ou a caça apodrecessem sem que antes pudesse consumi-los, ele estaria ofendendo as leis comuns da natureza e tornava-se passível de punição; teria usurpado a parte de seu vizinho, pois não tinha nenhum direito, além daqueles ditados por seu uso, a qualquer deles, para que pudesse proporcionar-lhes as conveniências da vida. (LOCKE, 2005, p. 418-419).

Este mesmo raciocínio pode ser usado para legitimar a propriedade da terra. Não há uma contradição nisso, no pensamento de Locke (2005), pois, devido à quantidade quase ilimitada de terras boas, essa apropriação individual não impediria que outros fizessem o mesmo.

\begin{abstract}
Mas, sendo agora a principal questão da propriedade não os frutos da terra e os animais que destes subsistem, e sim a própria terra, como aquilo que tem em si e carrega consigo todo o resto, creio que está claro que, também neste caso, a propriedade é adquirida como no caso anterior. A extensão de terra que um homem pode arar, plantar, melhorar e cultivar e os produtos dela que é capaz de usar constituem sua propriedade. Mediante o seu trabalho, ele por assim dizer, delimita para si parte do bem comum. (LOCKE, 2005, p.412-413)
\end{abstract}

A regra de apropriação, formulada pela revelação e pela razão, seria que cada um poderia se apropriar daquilo que, com o seu trabalho, pudesse retirar da terra, sem estragar, valendo, da mesma forma a uma extensão de terra explorada pelo trabalho individual. A propriedade seria fundamentada no direito dos homens de se apropriar, pelo trabalho, de tudo que houvesse na natureza para sua sobrevivência. Ao apropriar-se da terra, fazendo benefícios com o seu trabalho, o ser humano eleva a produtividade da humanidade em geral. Uma terra cultivada produz dez, cem vezes mais do que uma sem a interferência humana. Porém, como vimos, pela perecibilidade dos produtos da natureza, não é legítimo ao proprietário se apoderar de mais do que o necessário ao seu sustento, deixando estragar o excedente. Para resolver a perecibilidade da maioria das coisas úteis aos seres humanos, estes aceitaram o dinheiro como 
forma de manter a riqueza. Apesar dos metais terem poucas utilidades, podem, por meio desse acordo tácito, preservarem a riqueza e assim acumular fortunas. O princípio aqui é não estragar o que foi retirado da terra. Surge então a possibilidade da troca entre produtos ou entre produto e um metal, com qualidades monetárias.

Se cedesse uma parte a outra pessoa, de modo que não se estragasse inutilmente em
suas mãos, essa parte também teria sido usada. E também, se trocasse algumas
ameixas que se teriam estragado em uma semana por nozes de que se poderia
alimentar durante um ano, não causaria dano algum; (...) Mais uma vez, se trocasse
suas nozes por um pedaço de metal cuja cor lhe agradasse, ou sua lenha por uma pedra
brilhante ou um diamante, e as guardasse consigo por toda a vida, não estaria
invadindo o direito alheio e poderia acumular tantas dessas coisas duráveis quanto lhe
aprouvesse; o exagero nos limites de sua justa propriedade não residia na extensão de
suas posses, mas no perecimento inútil de qualquer parte delas (LOCKE, 2005, p.
426).

Com a introdução do dinheiro ou da troca entre produtos com possibilidade de conservar-se por muito tempo, abre a possibilidade de acumular riqueza. A origem da acumulação se explica pela laboriosidade de uns enquanto outros preferem o descanso. E uma vez conquistada a propriedade, por meio desse trabalho diligente e operoso, esta não poderia ser questionada por outra pessoa.

É a partir desta fundamentação teórica do trabalho como origem da riqueza que Adam Smith (1987) escreveu sua obra. Tendo uma concepção de sociedade essencialmente natural, ele vai compreender a sociedade como evoluindo de estágios em estágios até atingir o ponto culminante do capitalismo como modo de organização dos países. Nesse sentido, a sociedade passou por vários períodos - caçadores, pastores, agricultores e comércio- até se tornar a sociedade capitalista do século XVIII, momento em que escreve a Riqueza das Nações. A sua interpretação sobre a passagem de um período a outro, por meio do que podemos deduzir uma concepção de história do autor, é que há uma evolução, no sentido da existência de uma sociedade funcionando nos moldes capitalista, baseada na propriedade privada e na liberdade de comércio, legitimada pelo direito natural e com as instituições como justiça e governo.

Esta evolução, que se dá do período dos caçadores ao de comércio, é movida pela propensão natural dos indivíduos à troca. Por meio desta propensão, foi possível ao ser humano executar a divisão do trabalho, questão essencial que possibilitou que cada indivíduo se especializasse numa atividade específica do processo de produção, e não fazendo todo o produto, aumentando, assim, a produtividade e a riqueza da economia.

A posterior sociedade capitalista seria, portanto, o ideal de sociabilidade e promoveria mais igualdade, principalmente em relação à sociedade feudal, à qual Smith (1996) e os liberais lutavam contra. Proprietário de seu trabalho, cada trabalhador poderia, de forma 
igual (assim todos se beneficiariam e seria uma relação justa) trocar, no mercado, a quantidade de produtos que excedesse o seu consumo pessoal. Considerando que todos os demais trabalhadores estavam nessa mesma situação (o mercado faria com que o trabalhador que produz uma determinada mercadoria encontrasse quem estivesse interessado em comprar esta mercadoria, e assim obter a mercadoria que estivesse interesse) aconteceria um equilíbrio geral na sociedade por meio do mercado. De acordo com Smith (1996, p.70):

É a grande multiplicação das produções de todos os diversos ofícios- multiplicação
essa decorrente da divisão do trabalho - que gera, em uma sociedade bem dirigida,
aquela riqueza universal que se estende até as camadas mais baixas do povo. Cada
trabalhador tem para vender uma grande quantidade do seu próprio trabalho, além
daquela de que ele mesmo necessita; e pelo fato de todos os outros trabalhadores
estarem exatamente na mesma situação, pode ele trocar grande parte de seus próprios
bens por uma grande quantidade, ou-o que é a mesma coisa - pelo preço de grande
quantidade de bens desses outros. Fornece-lhes em abundância aquilo de que carecem,
e estes, por sua vez, com a mesma abundância, lhe fornecem aquilo de que ele
necessita; assim é que em todas as camadas da sociedade se difunde uma abundância
geral de bens.

A troca, no entanto, é específica dos seres humanos, proporcionada pela capacidade

de falar e raciocinar que estes têm e que os diferencia dos demais animais. Seria, então, a diferença fundamental entre os seres humanos e os demais animais.

Não é nossa tarefa investigar aqui se essa propensão é simplesmente um dos princípios
originais da natureza humana, sobre o qual nada mais restaria a dizer, ou se - como
parece mais provável - é uma conseqüência necessária das faculdades de raciocinar
e falar. De qualquer maneira, essa propensão encontra-se em todos os homens, não se
encontrando em nenhuma outra raça de animais, que não parecem conhecer nem essa
nem qualquer outra espécie de contratos. (...) Ninguém jamais viu um cachorro fazer
uma troca justa e deliberada de um osso por outro, com um segundo cachorro.
Ninguém jamais viu um animal dando a entender a outro, através de gestos ou gritos
naturais: isto é meu, isto é teu, estou disposto a trocar isto por aquilo. (SMITH, 1996,
p.73)

Assim, tendo em vista que a construção da sociedade, na concepção de Smith (1996), fundamenta-se em indivíduos que têm, por força da fala e do raciocínio, a propensão natural a troca (portanto, pressupõe o mercado como o lugar de realização desta troca, e de intercâmbio entre as pessoas) de produtos do trabalho como a forma de garantir sua existência material, analisaremos nos seus determinantes, o coroamento da sociedade capitalista.

\section{A ORIGEM DAS DESIGUALDADES SOCIAIS}

A divisão do trabalho e sua consequente força produtiva eram a base para explicar a produção de riquezas nesta sociedade. A constatação é que o trabalho produz a riqueza. Esta concepção remonta a outros pensadores antes de Smith (1996) e da Escola Clássica de Economia Política, como vimos em Locke (2005), que teorizaram numa clara oposição às 
concepções feudais em que a riqueza era algo divino. Nesse sentido, o trabalho será considerado como fundamental na construção da riqueza e legitimador da propriedade privada e da sociedade capitalista. Só depois da consolidação de tal compreensão é que Smith (1996) se ocupa em entender e justificar como esta sociedade se desenvolveu e como, a partir da constatação de suas falhas ou desvios, o Estado pode atuar, tendo a educação como um desses meios para minimizar esses defeitos

Mas como surge a desigualdade social, se a riqueza se limita à propriedade adquirida com o trabalho pessoal? O dinheiro, que para Locke (20005) surge de um acordo entre os seres humanos, permitiu, pelas suas qualidades intrínsecas (o ouro, ao contrário dos alimentos, poderia se conservar para além do consumo imediato) mediante a troca, conservar aqueles produtos da natureza- como a carne- por mais tempo do que o consumo imediato.

Deus deu o mundo aos homens em comum; (...) Deu-o para o uso dos diligentes e
racionais (e o trabalho haveria de ser o seu título de propriedade), e não para a fantasia
e a cobiça dos rixentos e litigiosos. Aquele que tivesse para melhorar a terra tão boa
quanto aquela que já estivesse tomada não precisaria queixar-se nem deveria meter-
se com a que já estivesse melhorada pelo trabalho alheio; caso o fizesse, ficaria claro
que desejava o benefício dos esforços alheios, ao qual não tem direito, e não ao solo
que Deus lhe dera em comum com os outros para trabalhar e do qual haveria tanto
sobrado quanto o que já fosse possuído, e mais do que ele poderia usar ou do que seu
esforço poderia abarcar (LOCKE, 2005, p. 414).

São os indivíduos que, a partir do seu trabalho, conquistam a propriedade privada. As desigualdades sociais, que Smith (1996) reconhece, é explicada pela atitude laboriosa de uns, como foi fundamentada por Locke (2005) enquanto outros, os desprovidos de propriedade, preferem os prazeres da vida ao trabalho árduo. Nesse sentido, (...) "a avareza e a ambição dos ricos e, por outro lado, a aversão ao trabalho e o amor à tranqüilidade atual e ao prazer, da parte dos pobres, são as paixões que levam a invadir a propriedade — paixões muito mais constantes em sua atuação e muito mais gerais em sua influência. (SMITH,1996, p.188).

Uma vez estabelecida a sociedade comercial, agora surge a necessidade de instituições sociais que a mantenham, uma vez que ao evoluir de estágio, com estabelecimento da propriedade privada, há a necessidade de protegê-la, posto que, apesar de sua origem ser o trabalho individual, nem todos os seres humanos se dedicaram igualmente ao trabalho, e portanto, não merecem desfrutar desse bem ganho por outro. Aqui surge a justiça como forma de proteger aqueles que se dedicaram ao trabalho em detrimento do prazer: nos períodos anteriores, quando a propriedade privada não estava dominante, cujo valor "não excedia três dias de trabalho", não havia necessidade de uma justiça, pois a desavenças se resumiam a questões pessoais e não envolviam o patrimônio. 


\section{AS FONTES DE RENDA}

Com o advento do modo de produção capitalista, com suas determinações explícitas, como a existência da propriedade privada, o desenvolvimento das forças produtivas do trabalho e a manufatura na grande fábrica, faz-se necessário, agora por meios não-naturais, possibilitar que atividades tidas como fundamentais para a manutenção da sociedade como um todo, seja viabilizada. A educação também se insere nesse rol de atividades que podem ser custeada pela sociedade via tributos, haja vista que, ao contrário de períodos anteriores, esta não se dá de forma direta da relação entre as pessoas no seu trabalho. Assim, antes de seguimos nessa discussão, veremos como se distribuem as divisões da renda nessa sociedade evoluída (capitalista) e como as instituições foram criadas para garantir a manutenção delas (renda).

Com o estágio da manufatura desenvolvido, a sociedade capitalista se apresenta na sua forma mais completa. Aqui já temos o resultado da propensão do ser humano à troca e a consequente composição da sociedade em trabalhadores, capitalista e donos da terra, cada qual com a sua remuneração correspondente à classe a qual pertence. Nesse sentido, pode-se dividir as rendas provenientes da seguinte forma: salário, lucro, juros (esta derivada do capital emprestado) e renda fundiária.

Todo aquele que aufere sua renda de um fundo que lhe pertence necessariamente a
aufere de seu trabalho, de seu patrimônio ou de sua terra. A renda auferida do trabalho
denomina-se salário. A renda auferida do patrimônio ou capital, pela pessoa que o
administra ou o emprega, chama-se lucro. A renda auferida por uma pessoa que não
emprega ela mesma seu capital, mas o empresta a outra, denomina-se juros ou uso do
dinheiro. É a compensação que o tomador paga a quem empresta, pelo lucro que pode
auferir fazendo uso do dinheiro. (...) A renda auferida integralmente do arrendamento
da terra é denominada renda fundiária, pertencendo ao dono da terra. (SMITH, 1996,
p104).

São a partir dessas fontes de renda que Smith (1996) pensa como a renda é distribuída na sociedade. Assim, o pagamento de um tributo origina-se de uma dessas fontes. Smith (1996, p104):

Todas as taxas, impostos; e toda a renda ou receita fundada neles, todos os salários, pensões e anuidades de qualquer espécie, em última análise provêm de uma ou outra dessas três fontes originais de renda, sendo pagos, direta ou indiretamente, pelos salários do trabalho, pelos lucros do capital ou pela renda da terra.

No entanto, acontece de a mesma pessoa ser proprietária (Smith reconhece que isso é casual) de mais de uma fonte de renda. Assim, o trabalhador, que possui capital suficiente para produzir mercadorias, e ele mesmo as vende no mercado, receberá as remunerações correspondentes ao salário e ao lucro do capital. Da mesma forma o proprietário de terra, que é 
cultivada por ele mesmo, deve receber a parcela correspondente à renda da terra e o salário de cultivo da terra.

\begin{abstract}
Uma pessoa que cultiva uma parte de sua própria terra, depois de pagar as despesas do cultivo, deve receber tanto a renda que cabe ao proprietário da terra quanto o lucro de quem a explora. Um manufator independente, que tem capital suficiente tanto para comprar materiais como para manter-se até poder levar seu produto ao mercado, deve ganhar tanto os salários de um trabalhador contratado por um patrão quanto o lucro que o patrão realiza pela venda do produto do trabalhador. Um horticultor que cultiva pessoalmente sua própria horta desempenha ao mesmo tempo três funções: proprietário da terra, responsável direto pela exploração da terra e trabalhador. Consequentemente, seu produto deve pagar-lhe a renda que cabe ao primeiro, o lucro que cabe ao segundo e os salários que cabem ao terceiro. No entanto, comumente tudo é considerado como proventos de seu trabalho. Nesse caso, tanto a renda da terra como o lucro são confundidos como salários. (SMITH, 1996, p105).
\end{abstract}

Dessa forma, fica bem clara a divisão da sociedade nos segmentos de trabalhadores, proprietários de terra e de capital. Havendo, inclusive, como mencionado acima, a possibilidade, em alguns casos, de uma mesma pessoa ser proprietária de mais de um fonte de renda (trabalhar a própria matéria-prima ou cultivar a própria terra). É o caso de quando o trabalhador possui um capital acumulado que lhe permite comprar as matérias-primas necessárias ao processo produtivo e, ao mesmo tempo, suprir-se dos bens necessários a sua sobrevivência, ou seja, seu salário. Nesse caso, o trabalhador é, ao mesmo tempo, patrão e empregado, auferindo, assim, o que lhe cabe enquanto trabalhador e proprietário de capital. No entanto, de acordo com Smith (1996, p. 1117):

Às vezes, ocorre realmente que um trabalhador independente tenha capital suficiente
tanto para comprar os materiais para seu trabalho, como para manter-se até completá-
lo. (...) Contudo, esses casos não são muito freqüentes, e em todas as partes da
Europa, para cada trabalhador autônomo existem vinte que servem a um patrão;
subentende-se que os salários do trabalho são em todos os lugares como geralmente
são, quando o trabalhador é uma pessoa, e o proprietário do capital que emprega o
trabalhador é outra pessoa.

A relação normal é que haja trabalhadores e patrões, sendo esses casos em que a mesma pessoa trabalha e detém os meios de produção um acaso isolado. A regra da sociedade é haver o capitalista que compra matérias-primas e contrata o trabalhador e que, com o pagamento do salário, o mantém enquanto a produção não é realizada (a manutenção do trabalhador entre a compra dos insumos e a venda das mercadorias é, segundo Smith (1996), bancado pelo capitalista). O capitalismo, portanto, é o ideal de sociedade.

\title{
5 O FINANCIAMENTO DE ATIVIDADES PELA COLETIVIDADE: EM DESTAQUE A EDUCAÇÃO
}

A partir da análise de sociabilidade liberal, pode-se deduzir/compreender o papel 
da educação formal, bem como as formas e motivos pelos quais deve ser ou não ser custeada, vislumbrando o bem da coletividade. A concepção de sociabilidade de Smith (1996) é marcada por uma sociedade dividida em classes e que são remuneradas a partir desta condição. $\mathrm{O}$ capitalismo, e suas instituições, como o governo e o Estado, considerado o estágio mais avançado que a sociedade pode alcançar, funciona a partir de leis naturais. É nesse sentido que Smith (1996) procura, em sua obra, deduzir quais são essas leis. Assim, chegado ao ponto máximo, verifica-se que algumas atividades necessárias a esta sociedade devem ser realizadas pela iniciativa privada, enquanto outras, cuja magnitude, quantidade de recursos e grau de beneficio a coletividade, devem ser custeadas por todos.

Esses gastos, de acordo com o período de evolução, há uma maior necessidade, conforme sejam coletivos, à medida que a sociedade avança de um grau menor para um maior. Assim, nos períodos de caçadores, pastores e agricultores, os gastos com defesa eram feitos pelo próprio trabalhador, pois a atividade de trabalho se estendia para a guerra. Nesses estágios, esses gastos não eram tão visíveis como no modo mais avançado, quando existe a propriedade privada e a divisão do trabalho proporcionou um aumento da riqueza que precisa ser protegida pela força (Defesa) e pelas Leis (Justiça).

Dentre os deveres do Estado, estão os gastos com a Defesa e com o sustento do soberano, com a Justiça, com as obras e com as instituições públicas. Destas, as duas primeiras (defesa e sustento do soberano) são beneficiados, sem distinção, todos os membros do país. Os gastos com a Justiça, com as obras e as instituições públicas, dependendo de cada caso, pode beneficiar parcelas da população, e assim deveria ser custeada somente por quem se beneficiou diretamente. É o caso de uma estrada que poderia, apesar de beneficiar a todos, ser cobrado um pedágio de manutenção para aquele que efetivamente usou a estrada ou, no caso da justiça, aquele que causou a demanda deveria pagar na medida que foi beneficiado, e dessa forma o custo não seria pago por toda a sociedade. Assim, no total temos os seguintes gastos, de acordo com Smith (1996, p. 198) que devem ser da sociedade como um todo:

Depois das instituições e obras públicas necessárias para a defesa da sociedade e para a administração da Justiça - ambas já mencionadas - , as demais obras e instituições públicas consistem sobretudo nas que se destinam a facilitar o comércio da sociedade e nas que visam a promover a instrução do povo. As instituições destinadas à instrução dividem-se em dois tipos: as que visam à educação da juventude e as que visam à instrução dos cidadãos de todas as idades. (grifos nossos).

Nesse sentido, a ideia de Smith (1996) é que cada despesa ou gasto possa ser bancado por quem se beneficiou diretamente dele. Assim, em termos de sociedade como um todo, os gastos e as receitas se compensariam. E quanto à educação especificamente, temos um 
tipo voltado para a juventude e outro, chamada de instrução, para toda a população.

Em “Os gastos das instituições para a educação da juventude”, Smith (1996) defende que estas instituições podem garantir uma receita suficiente para cobrir seus gastos, oriunda do pagamento feito pelo estudante. Esta é a regra defendida por Smith (1996), a qual ele chama de "rendimento natural". A manutenção das instituições educacionais deve acontecer com esta remuneração, não saindo da receita geral do país. Embora, em alguns casos, possa provir de uma dotação pública:

A dotação provém, em toda parte, sobretudo de algum rendimento local ou provincial, do arrendamento de uma propriedade territorial, ou dos juros de alguma soma de dinheiro concedida e confiada à gestão de curadores para esse fim específico, ora pelo próprio soberano ora por algum doador particular. (SMITH, 1996, p. 228).

Smith (1996, p. 228) se questiona se essas dotações públicas têm contribuído para atingir os objetivos para os quais foram criados.

Terão essas dotações públicas contribuído, de modo geral, para atingir o objetivo de sua instituição? Terão elas contribuído para estimular a diligência e melhorar a capacidade dos professores? Terão conduzido o curso da educação para objetivos mais úteis, tanto para o indivíduo como para o público, do que os objetivos para os quais teriam sido aplicadas espontaneamente?

Repensando o uso desta dotação pública, como é previsível pela concepção de sociedade defendida pelo autor, ele sugere que tais recursos seriam mais eficientemente aplicados se não tivessem a interferência estatal. Smith (1996) começa discorrendo como um profissional se empenha no seu ofício de forma geral para chegar ao professor. Quanto maior a necessidade de demonstrar emprenho em uma profissão, maior será o esforço do profisssional no desenvolvimento de suas atividades. E este empenho aumentará à medida que os elementos/fundamentos da sociabilidade capitalista estejam presentes: concorrência livre e rivalidade entre ofertadores de trabalho, com a consequente eliminação do concorrente, são estimulantes para que o trabalhador execute uma quantidade maior possível de valor, em troca de seus serviços. Esta seria a melhor forma de motivar um profissional (seja ele professor ou advogado) para que este possa se empenhar na sua atividade.

Em toda profissão, o empenho da maior parte dos que a exercem é sempre proporcional à necessidade de que estes têm de demonstrar aquele empenho. Essa necessidade é maior em relação àqueles cujos emolumentos profissionais constituem a única fonte da qual esperam auferir fortuna ou a menos seus rendimentos e sua subsistência normais. (...) (para tanto) devem, no decurso de um ano, executar um certo volume de serviço de determinado valor; e, quando a concorrência é livre, a rivalidade entre os concorrentes, que, sem exceção, se empenham em eliminar-se mutuamente do emprego, obriga cada um a procurar executar seu trabalho com certo grau de precisão. (...) Ao contrário, os grandes objetivos, por si sós, e se não forem apoiados na necessidade de aplicação, raramente têm sido suficientes para originar algum empenho considerável (SMITH, 1996, p.228 e 229). 
Assim é o caso da profissão dos professores. Estes serão mais ou menos aplicados em suas atividades docentes na mesma proporção de suas necessidades. Temos aqui alguns modelos de pagamentos dos professores e que influencia diretamente, segundo Smith, no rendimento do trabalho docente. Há o modelo em que a remuneração do professor é composta, além do salário, que representa menor parte, de pagamentos oriundos dos estudantes, que segundo Smith (1996), representaria a maior parte da remuneração. O salário fixo contribuiria, neste caso, para a desmotivação do professor, enquanto que a parte variável, dependente do desempenho do professor seria testado por meio do sucesso, conferido por meio de pagamento, que este provocasse nos estudantes.

A necessidade de aplicação, conquanto sempre mais ou menos reduzida, não é, neste caso, inteiramente eliminada. A reputação na profissão é ainda de alguma importância para o professor, que depende um tanto, outrossim, da afeição, da gratidão e do conceito favorável dos que ouviram suas preleções; e a melhor maneira de despertar esses sentimentos favoráveis é merecê-los, isto é, demonstrar capacidade e diligência no desempenho de cada um de seus deveres. (SMITH, 1996, p.229).

Como modelo ideal, podemos fazer a distinção (na forma de remuneração do professor) que Smith faz de escola e universidade na Inglaterra. Nas escolas, em que a quase totalidade da remuneração do professor é via pagamento dos alunos, temos que, conforme Smith (1996, p. 232) salienta "ensina-se aos jovens — ou ao menos pode-se ensinar-lhes grego e latim, isto é, tudo aquilo que os professores pretendem ensinar, ou que, como se acredita, deveriam ensinar." Nas universidades, por sua vez, "não se ensinam à juventude as ciências que essas corporações têm por finalidade ensinar, e nem sempre ela consegue encontrar nas mesmas, meios adequados para aprendê-las."

No entanto, neste exemplo acima, no qual Smith exalta como melhor o ensino no qual é pago pelo estudante, ele reconhece que na universidade pública é produzido um saber que, de outra forma, não seria produzido, haja vista que a procura é que determinaria a oferta.

Poder-se-ia talvez alegar que, sem dúvida, não é muito bom o ensino das matérias que se costuma lecionar nas universidades. Todavia, não fossem essas instituições, tais matérias geralmente não teriam sido sequer ensinadas, e tanto o indivíduo como a sociedade sofreriam muito com a falta dessas matérias importantes para a educação. (SMITH, 1996, p. 232):

Por esse modelo, percebemos que a melhor forma de trabalhar a educação é por meio do ensino no qual estudante e professores são livres para decidirem como estudar e ensinar, sendo a procura um elemento fundamental para criar a necessidade e, tornada livre, proporcionar o melhor produto. Assim, referindo-se aos gregos e romanos clássicos, ele constata que, com exceção das atividades militares, o Estado não intervinha na formação de 
outras habilidades. Conforme Smith (1996, p.242), no entanto:

Ao que parece, porém, encontraram-se mestres para instruir as melhores pessoas entre essas nações, em todo ofício e ciência em que as circunstâncias de sua sociedade tornavam necessário ou conveniente instruí-las. A procura dessa instrução produziu aquilo que sempre produz: o talento para ministrar tal instrução; e a emulação, que uma irrestrita concorrência nunca deixa de despertar, parece ter levado esse talento a altíssimo grau de perfeição. (grifos nossos).

Smith (1996) compara esta relação entre professor e estudante com o comerciante e suas mercadorias. Equivale o salário fixo do professor que contribui para que este seja negligente no seu ofício, como o comerciante que recebe subsídio para sua atividade comercial. Este terá vantagem na concorrência com outros comerciantes que ofertam a mesma mercadoria. Aqui o concorrente estará fadado à penúria, pois se vender a mercadoria em torno do preço do comerciante que tem subsídio, não vai conseguir se manter no mercado. Ao passo que, se vender acima deste preço, terá, provavelmente, tão poucos cliente que também não se manterá no mercado. Assim é o professor particular, o equivalente ao comerciante sem subsídio, na concorrência com professor público que recebe salário fixo.

Nos tempos modernos, a diligência dos professores públicos é mais ou menos
deturpada pelas circunstâncias que os tornam mais ou menos independentes de seu
sucesso e de sua reputação em suas respectivas profissões. Ademais, seus salários
colocam o professor particular, que pretendesse concorrer com eles, na mesma
situação em que estaria um comerciante que tentasse praticar o comércio sem um
subsídio, devendo competir com aqueles que comercializam favorecidos por um
subsídio considerável. Se ele vender suas mercadorias mais ou menos ao mesmo
preço, não poderá auferir o mesmo lucro que eles, e sua sorte - a sua infalível será,
no mínimo, a pobreza e a penúria, senão a falência e a ruína. Se tentar vendê-las muito
mais caro, provavelmente terá tão poucos clientes que sua situação não melhorará
muito. (SMITH, 1996, p.242).

Dessa forma, a atuação do Estado no ensino público, ao não incentivar a concorrência entre professores, fez com que a oferta educacional fosse formada por docente que negligenciam a sua atuação. Aqueles professores sem salário fixo, da mesma forma que o comerciante sem subsídio, está numa posição desfavorável, e portanto sem condição de ser um bom professor, em relação ao professor de uma instituição pública. A intervenção estatal, nesse caso, funciona como uma forma de desqualificar a oferta de professores particulares:

É por todas essas razões que o professor particular de qualquer ciência comumente
ensinada nas universidades é, na época moderna, geralmente considerado como
pertencente à categoria mais baixa de letrados. (...) Dessa forma, as dotações
concedidas às escolas e colégios não somente corromperam a diligência dos
professores públicos, senão também tornaram quase impossível conseguir bons
professores particulares. (SMITH, 1996, p.243): Diante deste quadro, Smith se questiona qual deve ser, então, a forma de intervir do Estado. E conclui que "Seria lícito então perguntar: não deverá o Estado dispensar nenhuma 
atenção à educação das pessoas? Ou, se alguma atenção deve dispensar, quais são as matérias que deve reconhecer, nas diversas categorias da população? E de que maneira as deverá reconhecer?” (1996, p. 243). O autor aqui reconhece que existem parcelas da população que, independentemente da atuação do governo, possuem todas as condições de viver nesta sociedade. Paralelo, reconhece que outras parcelas estão desprovidas dessa possibilidade de existir nesta sociedade, com suas regras, sem uma atuação do Estado.

É o caso, por exemplo, da importante questão das consequências da divisão do trabalho. Esta que é considerada como a grande responsável pelo aumento da riqueza, ao mesmo tempo, tem efeitos nefastos para os trabalhadores, que constitui a maioria da população.

Com o avanço da divisão do trabalho, a ocupação da maior parte daqueles que vivem do trabalho, isto é, da maioria da população, acaba restringindo-se a algumas operações extremamente simples, muitas vezes a uma ou duas. Ora, a compreensão da maior parte das pessoas é formada pelas suas ocupações normais. O homem que gasta toda sua vida executando algumas operações simples, cujos efeitos também são, talvez, sempre os mesmos ou mais ou menos os mesmos, não tem nenhuma oportunidade para exercitar sua compreensão ou para exercer seu espírito inventivo no sentido de encontrar meios para eliminar dificuldades que nunca ocorrem. (SMITH, 1996, p.244)

Diante deste quadro gerado pela sociedade comercial é que Smith (1996) propõe um ensino para esta parcela de trabalhadores que não dispõem de condições de estudar. A proposta neste caso seria que o Estado construísse escolas direcionadas a esse público que tem pouco tempo para se dedicar a educação. Os conhecimentos considerados essenciais seriam a leitura, a escrita e a matemática.

Embora, porém, as pessoas comuns não possam, em uma sociedade civilizada, ser tão
bem instruídas como as pessoas de alguma posição e fortuna, podem aprender as
matérias mais essenciais da educação - ler, escrever e calcular - em idade tão jovem,
que a maior parte, mesmo daqueles que precisam ser formados para as ocupações mais
humildes, têm tempo para aprendê-las antes de empregar-se em tais ocupaços. Com
gastos muito pequenos, o Estado pode facilitar, encorajar e até mesmo impor a quase
toda a população a necessidade de aprender os pontos mais essenciais da educação
(SMITH, 1996, p.244).

Estas escolas seriam construídas pelo Estado, mas o financiamento seria feito pelo próprio trabalhador. A ideia é que este pagamento seja tão pouco que uma família de trabalhador possa custear esse pagamento. Aqui mais uma vez Smith (1996) deixa clara sua concepção de que o ensino sendo bancado pelo pagamento de salário fixo ao professor, a dedicação deste seria negligenciada.

O Estado pode facilitar essa aprendizagem elementar criando em cada paróquia ou distrito uma pequena escola, onde as crianças possam ser ensinadas pagando tão pouco que até mesmo um trabalhador comum tem condições de arcar com este gasto, sendo o professor pago em parte, não totalmente, pelo Estado, digo só em parte 
porque, se o professor fosse pago totalmente, ou mesmo principalmente, como dinheiro do Estado, logo começaria a negligenciar seu trabalho. (SMITH,1996, p.246).

O conhecimento, no entanto, não é o objetivo imediato dessa instrução incentivada pelo Estado. A educação pode estar ligada a interesses muito mais prático do que formar pessoas com capacidade de discernimento. Essa instrução mínima não favorece uma formação integral, a qual todas pessoas tinha acesso nos estágios anteriores ao domínio do capital nas relações de produção. Nesta sociedade, como está claro nas citações de Smith, há uma divisão entre os que desenvolvem o intelecto (os que têm tempo e dinheiro para isso), com todas as possibilidades de aprendizado, e aqueles que, tendo que garantir sua existência material, unicamente a partir da venda do seu trabalho, têm acesso a alguns conhecimentos mínimos necessários para ser trabalhador e não se revoltar.

\begin{abstract}
Ainda que o Estado não aufira nenhuma vantagem da instrução das camadas inferiores do povo, mesmo assim deveria procurar evitar que elas permaneçam totalmente sem instrução. Acontece, porém, que o Estado aufere certa considerável vantagem da instrução do povo. Quanto mais instruído ele for, tanto menos estará sujeito às ilusões do entusiasmo e da superstição que, entre nações ignorantes, muitas vezes dão origem às mais temíveis desordens. Além disso, um povo instruído e inteligente sempre é mais decente e ordeiro do que um povo ignorante e obtuso. (SMITH,1996, p. 249).
\end{abstract}

As ideias de Smith (1996) até aqui analisadas, como também na história da educação (MANACORDA, 2010) evidenciam boa parte das concepções de escola pública que fosse também para todos, laica e mantida pelo Estado, derivadas do projeto de sociedade iluminista e posta em prática pelas nações europeias durante o século XIX.

\title{
6 CONSIDERAÇÕES FINAIS
}

A partir da análise até aqui empreendida, que é de fundamental importância para a compreensão da atual conjuntura econômica que se instaurou no modelo capitalista neoliberal, é possível pontuar as principais ideias que consubstanciam as práticas econômicas liberais, defendidas por Adam Smith e suas interfaces.

Propriedade privada e desigualdade social, para o autor em questão, possuem interfaces pouco sutis. A propriedade seria fundamentada no direito dos homens de se apropriar da natureza, das terras e de tudo mais que Deus deu, para a sua sobrevivência. Ou seja, o trabalho é, não apenas fonte de riqueza, como também o que justifica a propriedade privada. Esta é a concepção natural de sociedade de Smith (1996). Nesta mesma lógica, a origem das desigualdades sociais se explica pela laboriosidade de uns enquanto outros preferem o descanso, os prazeres da vida. Sendo, portanto, justo, que a acumulação de riqueza daqueles 
não seja questionada. A justiça surge, portanto, para proteger a propriedade privada daqueles que se dedicaram ao trabalho em detrimento do prazer.

Sobre as fontes de renda, considere-se a divisão da sociedade nos segmentos de trabalhadores, proprietários de terra e de capitalista. Considere-se também que, em alguns casos, um trabalhador pode ser, ao mesmo tempo, patrão e empregado (mesmo que sejam raros, como reconhece Smith), sendo, portanto, proprietário de mais de um fonte de renda. A regra da sociedade é haver o capitalista que compra matérias-primas e contrata o trabalhador e que, com o pagamento do salário, o mantém enquanto a produção não é realizada (a manutenção do trabalhador entre a compra dos insumos e a venda das mercadorias é, segundo Smith (1996), bancado pelo capitalista).

Sobre educação e financiamento, Smith (1996) defende que o beneficiado com determinada ação a financie. Assim, o Estado pode pagar pela educação na medida em que esta beneficia a todos, pois forma pessoas menos propensas a se rebelar e também porque esses alguns conhecimentos básicos, essenciais para a vida na sociedade comercial, não serão adquiridos pelo próprio trabalhador se o Estado não intervier no sentido de incentivar tal atividade. Reitera-se, porém, que o pagamento feito ao professor deve ser incentivado para que seja feito pelo próprio trabalhador, pois do contrário o professor seria negligente com o seu ofício.

Numa sociedade baseada e dominada pela mercadoria, na qual tem o dinheiro como elemento fundamental para a realização desta, é de se esperar que toda atividade seja medida em termos quantitativos. A educação então aqui é mais uma determinação da mercadoria, com valor de troca e valor de uso. O valor de uso é limitado pelo valor de troca. Assim, aqueles com disponibilidade de dinheiro terão acesso a um conhecimento diferente daqueles que têm pouco ou quase nada para comprar educação.

O pensamento de Smith (1996) deve ser considerado no contexto em que o autor escreveu seus textos, numa época em que lutar contra os privilégios feudais era uma atitude revolucionária. Suas ideias devem ser contextualizadas para o momento atual e não simplesmente repetidas, como fazem os neoliberais, de forma acrítica.

\section{REFERÊNCIAS}

MANACORDA, Carlos Alighiero. História da Educação: da antiguidade aos nossos dias. 11. Ed. - São Paulo: Cortez, 2004. 
LOCKE, John. Dois tratados sobre o governo. Tradução de Julio Fischer. 2. ed. São Paulo: Martins Fontes, 2005.

SMITH, A. A riqueza das Nações. Rio de Janeiro: Abril Cultural, 1996. 